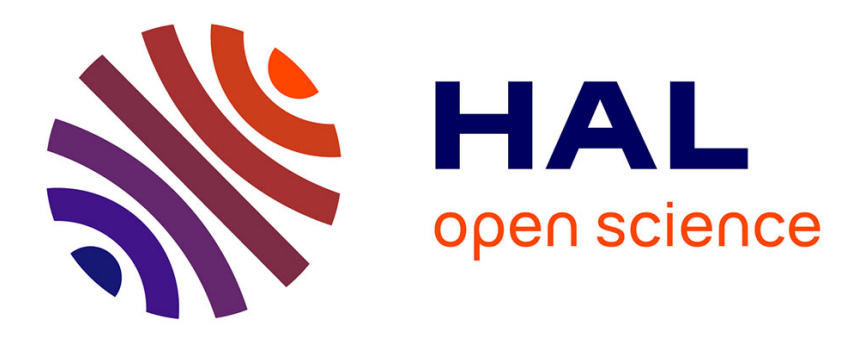

\title{
State estimation for a class of singular systems
}

Mohamed Darouach, Michel Zasadzinski

\section{To cite this version:}

Mohamed Darouach, Michel Zasadzinski. State estimation for a class of singular systems. International Journal of Systems Science, 1992, 23 (4), pp.517-530. hal-00143555

\section{HAL Id: hal-00143555 https://hal.science/hal-00143555}

Submitted on 25 Apr 2007

HAL is a multi-disciplinary open access archive for the deposit and dissemination of scientific research documents, whether they are published or not. The documents may come from teaching and research institutions in France or abroad, or from public or private research centers.
L'archive ouverte pluridisciplinaire HAL, est destinée au dépôt et à la diffusion de documents scientifiques de niveau recherche, publiés ou non, émanant des établissements d'enseignement et de recherche français ou étrangers, des laboratoires publics ou privés. 


\section{STATE ESTIMATION FOR A CLASS OF SINGULAR SYSTEMS}

M. DAROUACH and M. ZASADZINSKI

C.R.A.N., C.N.R.S., U.A. 821

Université de Nancy I

I.U.T. de Longwy, route de Romain, 54400 Longwy, FRANCE

The linear state estimation for a class of singular systems is formulated by using the sequential linear estimator solution developed in steady state systems. This procedure is based upon sequential processing of the covariance of the estimate arising from the solution of the least squares problem. The convergence conditions of the state estimate are established. An application to state and input estimation in the dynamic discrete system is presented.

\section{Notation}

$\rho(\mathrm{A})$ : $\quad$ spectral radius of matrix $A$

$\|\mathrm{A}\|: \quad$ norm of matrix $\mathrm{A}\left(\lambda_{\max }\left(\mathrm{A}^{\mathrm{T}} \mathrm{A}\right)\right)^{1 / 2}$

$\mathrm{A}>\mathrm{B}: \mathrm{A}-\mathrm{B}$ positive definite matrix

$A \geq B: A-B$ positive semi-definite matrix

\section{Introduction}

Singular systems were introduced to describe the dynamics of certain linear systems for which the standard state-space representation is not applicable. This type of process has been studied by a number of investigators (Luenberger 1977 and 1978, Verghese et al. 1981).

The problem of state estimation for discrete-time stochastic singular systems was studied by Dai (1989) who transformed the filtering problem for a singular system into an equivalent problem for a non singular system. However, no effort seems to have been made to develop a theory of state estimation in systems described by rectangular matrices. In this paper we present a new state estimation algorithm for a class of singular systems described by rectangular matrices.

This algorithm is based on the linear unbiased least-squares estimation method developed in steady state data reconciliation (Crowe et al. 1983 and Darouach 1986 and Darouach et al. 1989).

\section{Problem statement}

In this paper, we shall consider the singular system described by the following discrete model 


$$
-\mathrm{EX}_{\mathrm{i}+1}+\mathrm{B} \mathrm{X}_{\mathrm{i}}=0 \quad \mathrm{i}=1, \ldots, \mathrm{k}
$$

with the observations

$$
\mathrm{Z}_{\mathrm{i}}=\mathrm{X}_{\mathrm{i}}+\mathrm{v}_{\mathrm{i}}
$$

where $\mathrm{E}$ and $\mathrm{B}$ are $(\mathrm{n}, \mathrm{p})$ matrices, the state vector $\mathrm{X}_{\mathrm{i}}$ is of dimension $\mathrm{p}$, the measurement noise $v_{i}$ is a p-vector white-noise process with zero mean and known variance matrix $\mathrm{V}$.

The state estimation problem for the singular system (1)-(2) may be solved by the linear least squares method.

The equation (1) can be expressed as a single vector equation

$$
\Phi_{\mathrm{k}} \mathrm{X}=0
$$

with

$$
X=\left(\begin{array}{l}
X_{1} \\
: \\
X_{k+1}
\end{array}\right)
$$

and

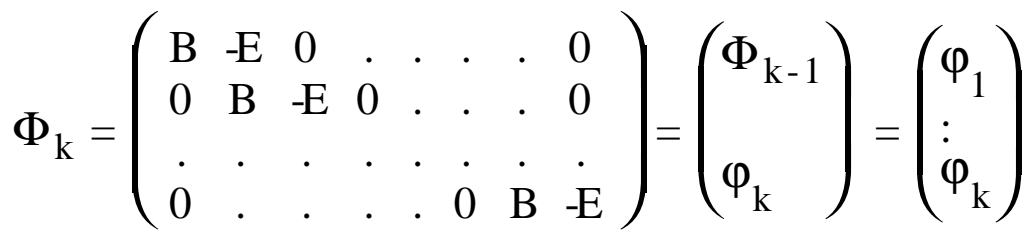

In the least squares sense, the problem is

$$
\begin{array}{ll}
\operatorname{minimize} & \mathrm{J}=\frac{1}{2}(\hat{\mathrm{X}}-\mathrm{Z})^{\mathrm{T}} \mathrm{V}^{-1}(\hat{\mathrm{X}}-\mathrm{Z}) \\
\text { subject to } & \Phi_{\mathrm{k}} \hat{\mathrm{X}}=0
\end{array}
$$

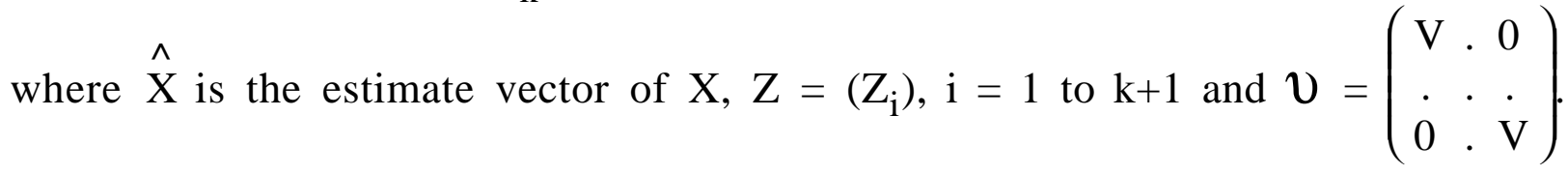

The solution of this problem is given by

$$
\hat{X}=\mathrm{P} Z
$$

where $\mathrm{P}$ is the projection matrix

$$
\mathrm{P}=\mathrm{I}-\cup \Phi_{\mathrm{k}}^{\mathrm{T}}\left(\Phi_{\mathrm{k}} \cup \Phi_{\mathrm{k}}^{\mathrm{T}}\right)^{-1} \Phi_{\mathrm{k}}
$$

This solution necessitates the inversion of the large scale matrix $\left(\Phi_{\mathrm{k}} \mathrm{V} \Phi_{\mathrm{k}}^{\mathrm{T}}\right)$. In this paper, we present the conditions of the uniqueness of the solution and we give its recursive scheme with the convergence conditions. 


\section{State estimation algorithm}

In the sequel we assume that matrix $(B \mid-E)$ is a full row rank matrix.

\section{Theorem 1}

Solution (6) is unique if and only if the matrix pencil ( $\mathrm{sE}-\mathrm{B}$ ) is of full row rank.

\section{Proof}

Solution (6) is unique if and only if $\Phi_{\mathrm{k}}$ is a full row rank matrix. If we suppose that the matrix pencil $(\mathrm{sE}-\mathrm{B})$ is not a full row rank matrix, this is equivalent to the existence of a row vector $\mathrm{x} \neq 0$ such that

$$
\mathrm{x}(\mathrm{sE}-\mathrm{B})=0
$$

where $\mathrm{s}$ is a complex number and $\mathrm{x}$ is a finite polynomial in $\mathrm{s}$

$$
\mathrm{x}(\mathrm{s})=\mathrm{x}_{0}-\mathrm{s} \mathrm{x}_{1}+\mathrm{s}^{2} \mathrm{x}_{2}-\ldots+(-1)^{\mathrm{k}} \mathrm{s}^{\mathrm{k}} \mathrm{x}_{\mathrm{k}} \quad\left(\mathrm{x}_{\mathrm{k}} \neq 0\right)
$$

where $\mathrm{k}$ is the minimum index (Gantmacher 1959).

Inserting (9) in (8) gives

$$
\left(\begin{array}{lll}
\mathrm{x}_{0} & \cdots & \mathrm{x}_{\mathrm{k}}
\end{array}\right) \Phi_{\mathrm{k}}=0
$$

and $\Phi_{\mathrm{k}}$ is not a full row rank matrix.

From (6) and (7) we have the following results :

(a) the expectation of estimate $\hat{\mathrm{X}}$

$$
\mathrm{E}(\mathrm{X})=X
$$

(b) the covariance matrix of $\hat{X}$

$$
\Sigma=\mathrm{E}\left[(\hat{\mathrm{X}}-\mathrm{X})(\hat{\mathrm{X}}-\mathrm{X})^{\mathrm{T}}\right]=v-v \Phi_{\mathrm{k}}^{\mathrm{T}}\left(\Phi_{\mathrm{k}} v \Phi_{\mathrm{k}}^{\mathrm{T}}\right)^{-1} \Phi_{\mathrm{k}}
$$

(c) the estimate (6) can be written as

$$
\hat{X}=\Sigma v^{-1} Z
$$

The computation of the estimate $\hat{\mathrm{X}}$ uses the expression of the covariance matrix $\Sigma$. If we note $\Sigma_{\mathrm{k}}$ the covariance matrix of the estimate $\hat{X}_{\mathrm{k}}$ based on the measurements in the presence of the constraints $\Phi_{k-1} \hat{X}=0$, the new estimate 
$\hat{X}_{k+1}$ based on the measurements and the additional constraint $\varphi_{k} \hat{X}=0$ is given by the following theorem.

\section{Theorem 2}

The linear unbiased least squares estimation of the state $\hat{X}_{k+1}$ is

$$
\hat{X}_{\mathrm{k}+1}=\left(\begin{array}{c}
\hat{\mathrm{X}}_{1 / \mathrm{k}+1} \\
\vdots \\
\hat{\mathrm{X}}_{\mathrm{k} / \mathrm{k}+1} \\
\hat{\mathrm{X}}_{\mathrm{k}+1 / \mathrm{k}+1}
\end{array}\right)
$$

where

$$
\begin{aligned}
& \hat{\mathrm{X}}_{\mathrm{k}+1 / \mathrm{k}+1}=\mathrm{Z}_{\mathrm{k}+1}+\mathrm{VE}^{\mathrm{T}} \Omega_{\mathrm{k}}\left(\mathrm{B} \hat{\mathrm{X}}_{\mathrm{k} / \mathrm{k}}-\mathrm{E} \mathrm{\textrm {Z } _ { \mathrm { k } + 1 }}\right) \\
& \Sigma_{(\mathrm{k}+1)(\mathrm{k}+1)}^{\mathrm{k}+1}=\mathrm{V}-\mathrm{VE}^{\mathrm{T}} \Omega_{\mathrm{k}} \mathrm{EV}
\end{aligned}
$$

and

$$
\begin{array}{ll}
\hat{X}_{j / k+1}=\hat{X}_{j / k}-\Sigma_{j k}^{k} B^{T} \Omega_{k}\left(B \hat{X}_{k / k}-E Z_{k+1}\right) & \text { for } j<k+1 \\
\sum_{j(k+1)}^{k+1}=\sum_{j k}^{k} B^{T} \Omega_{k} E V & \text { for } j<k+1 \\
\Omega_{k}=\left(B \Sigma_{k k}^{k} B^{T}+E V E^{T}\right)^{-1} &
\end{array}
$$

with $\Sigma_{11}^{1}=\mathrm{V}$ and $\Sigma_{\mathrm{ij}}^{\mathrm{k}}$ is the $(\mathrm{i}, \mathrm{j})$ block of $\Sigma_{\mathrm{k}}$ of dimension $(\mathrm{p}, \mathrm{p})$.

\section{Proof}

Consider the system described by

$$
\begin{aligned}
& Z=X+v \\
& \varphi_{1} X=0
\end{aligned}
$$

Its state estimate is given by

$$
\hat{\mathrm{X}}_{1}=\mathrm{P}_{1} \mathrm{Z}
$$

where $P_{1}=I-v \varphi_{1}^{T}\left(\varphi_{1} v \varphi_{1}^{\mathrm{T}}\right)^{-1} \varphi_{1}$

The covariance matrix of the estimate $\hat{X}_{1}$ is

$$
\Sigma_{1}=\mathrm{P}_{1} v=\left(\begin{array}{ccc}
\mathrm{V}-\mathrm{VB}^{\mathrm{T}} \Omega_{1} \mathrm{BV} & {\mathrm{V}-\mathrm{VB}^{\mathrm{T}} \Omega_{1} \mathrm{EV}}^{\mathrm{T}} & 0 \\
\mathrm{~V}^{\mathrm{V}} \mathrm{VE}^{\mathrm{T}} \Omega_{1} \mathrm{BV} & {\mathrm{V}-\mathrm{VE}^{\mathrm{T}} \Omega_{1} \mathrm{EV}} & 0 \\
0 & 0 & \mathrm{~V}
\end{array}\right)
$$

where

$$
\Omega_{1}=\left(\mathrm{B} \mathrm{V} \mathrm{B}^{\mathrm{T}}+\mathrm{EV} \mathrm{E}^{\mathrm{T}}\right)^{-1}
$$


Now with the following additional constraint

$$
\varphi_{2} \mathrm{X}=0
$$

the new estimate based on the knowledge of the measurement and constraints (21) and (25) is given by

$$
\hat{\mathrm{X}}_{2}=\mathrm{P}_{2} \hat{\mathrm{X}}_{1}=\Sigma_{2} v^{-1} \mathrm{Z}
$$

where $\Sigma_{2}$ is the covariance matrix of estimate $\hat{X}_{2}$

$$
\Sigma_{2}=\Sigma_{1}-\Sigma_{1} \varphi_{2}^{\mathrm{T}}\left(\varphi_{2} \Sigma_{1} \varphi_{2}^{\mathrm{T}}\right)^{-1} \varphi_{2} \Sigma_{1}
$$

More generally, $\hat{X}_{k+1}$ is given by

$$
\hat{\mathrm{X}}_{\mathrm{k}+1}=\mathrm{P}_{\mathrm{k}+1} \hat{\mathrm{X}}_{\mathrm{k}}=\Sigma_{\mathrm{k}+1} \mathrm{v}^{-1} \mathrm{Z}
$$

with

$$
\Sigma_{\mathrm{k}+1}=\Sigma_{\mathrm{k}}-\Sigma_{\mathrm{k}} \varphi_{\mathrm{k}}^{\mathrm{T}}\left(\varphi_{\mathrm{k}} \Sigma_{\mathrm{k}} \varphi_{\mathrm{k}}^{\mathrm{T}}\right)^{-1} \varphi_{\mathrm{k}} \Sigma_{\mathrm{k}}
$$

The covariance matrix $\Sigma_{\mathrm{k}}$ of estimate $\hat{\mathrm{X}}_{\mathrm{k}}$ can be written as a block matrix

$$
\Sigma_{\mathrm{k}}=\left(\begin{array}{cccc}
\Sigma_{11}^{\mathrm{k}} & \ldots & \Sigma_{1 \mathrm{k}}^{\mathrm{k}} & 0 \\
\Sigma_{\mathrm{k} 1}^{\mathrm{k}} & \ldots & \Sigma_{\mathrm{kk}}^{\mathrm{k}} & 0 \\
0 & \ldots & 0 & \mathrm{~V}
\end{array}\right)
$$

From (28) and (29) we have

$$
\mathrm{P}_{\mathrm{k}+1}=\left(\begin{array}{cccccc}
\mathrm{I} & 0 & \cdot & 0 & -\Sigma_{1 \mathrm{k}}^{\mathrm{k}} \mathrm{B}^{\mathrm{T}} \Omega_{\mathrm{k}} \mathrm{B} & \Sigma_{1 \mathrm{k}}^{\mathrm{k}} \mathrm{B}^{\mathrm{T}} \Omega_{\mathrm{k}} \mathrm{E} \\
\cdot & \cdot & \cdot & \cdot & \ldots & \ldots \\
0 & \cdot & 0 & \mathrm{I} & -\Sigma_{(\mathrm{k}-1) \mathrm{k}}^{\mathrm{k}} \mathrm{B}^{\mathrm{T}} \Omega_{\mathrm{k}} \mathrm{B} & \Sigma_{(\mathrm{k}-1) \mathrm{k}}^{\mathrm{k}} \mathrm{B}^{\mathrm{T}} \Omega_{\mathrm{k}} \mathrm{E} \\
0 & . & . & 0 & \mathrm{I}-\Sigma_{\mathrm{kk}}^{\mathrm{k}} \mathrm{B}^{\mathrm{T}} \Omega_{\mathrm{k}} \mathrm{B} & \Sigma_{\mathrm{kk}}^{\mathrm{k}} \mathrm{B}^{\mathrm{T}} \Omega_{\mathrm{k}} \mathrm{E} \\
0 & \cdot & \cdot & 0 & \mathrm{VE}^{\mathrm{T}} \Omega_{\mathrm{k}} \mathrm{B} & \mathrm{I}-\mathrm{VE}{ }^{\mathrm{T}} \Omega_{\mathrm{k}} \mathrm{E}
\end{array}\right)
$$

with

$$
\Omega_{\mathrm{k}}=\left(\varphi_{\mathrm{k}} \Sigma_{\mathrm{k}} \varphi_{\mathrm{k}}^{\mathrm{T}}\right)^{-1}=\left(\mathrm{B} \Sigma_{\mathrm{kk}}^{\mathrm{k}} \mathrm{B}^{\mathrm{T}}+\mathrm{EV} \mathrm{E}^{\mathrm{T}}\right)^{-1}
$$

In expression (30), only the value of the $\mathrm{k}^{\text {th }}$ block column of matrix $\Sigma_{\mathrm{k}}$ is required for the computation of $\mathrm{P}_{\mathrm{k}+1}$ and consequentely for the new covariance matrix $\Sigma_{\mathrm{k}+1}$. From the following relation

$$
\Sigma_{\mathrm{k}+1}=\mathrm{P}_{\mathrm{k}+1} \Sigma_{\mathrm{k}}
$$


we can deduce the $(\mathrm{k}+1)^{\text {th }}$ block column of matrix $\Sigma_{\mathrm{k}+1}$

$$
\left(\begin{array}{c}
\Sigma_{1(\mathrm{k}+1)}^{\mathrm{k}+1} \\
\vdots \\
\Sigma_{\mathrm{k}(\mathrm{k}+1)}^{\mathrm{k}+1} \\
\Sigma_{(\mathrm{k}+1)(\mathrm{k}+1)}^{\mathrm{k}+1}
\end{array}\right)=\left(\begin{array}{c}
\Sigma_{1 \mathrm{k}}^{\mathrm{k}} \mathrm{B}^{\mathrm{T}} \Omega_{\mathrm{k}} \mathrm{EV} \\
\vdots \\
\Sigma_{\mathrm{kk}}^{\mathrm{k}} \mathrm{B}^{\mathrm{T}} \Omega_{\mathrm{k}} \mathrm{EV} \\
\mathrm{V}-\mathrm{VE}^{\mathrm{T}} \Omega_{\mathrm{k}} \mathrm{EV}
\end{array}\right)
$$

and the estimate $\hat{\mathrm{X}}_{\mathrm{k}+1}$ is given in terms of $\hat{\mathrm{X}}_{\mathrm{k}} \mathrm{b} \mathrm{y}$

$$
\hat{X}_{k+1}=\left(\begin{array}{c}
\hat{X}_{1 / k+1} \\
\vdots \\
\hat{X}_{k / k+1} \\
\hat{X}_{k+1 / k+1}
\end{array}\right)=P_{k+1}\left(\begin{array}{c}
\hat{X}_{k} \\
Z_{k+1}
\end{array}\right)=P_{k+1}\left(\begin{array}{c}
\hat{X}_{1 / k} \\
\vdots \\
\hat{X}_{k / k} \\
Z_{k+1}
\end{array}\right)
$$

From (30)-(34), we can easily obtain the results of the theorem.

Resulting from this theorem :

(a) the convergence of estimate $\hat{X}_{k+1 / k+1}$ (15) can be obtained from the convergence of sequence $\Sigma_{\mathrm{kk}}^{\mathrm{k}}(16)$ or sequence $\Omega_{\mathrm{k}}(19)$,

(b) estimate $\hat{X}_{\mathrm{j} / \mathrm{k}+1}$ (17) converges to $\hat{\mathrm{X}}_{\mathrm{j} / \mathrm{k}}$ if sequence $\Sigma_{\mathrm{jk}}^{\mathrm{k}}$ (18) converges to zero when $\mathrm{k}$ increases,

(c) the initialization $\mathrm{V}$ of sequence $\Sigma_{\mathrm{kk}}^{\mathrm{k}}$ is positive definite.

\section{Remarks}

The study of the convergence of the algorithm is reduced to those of sequence $\Sigma_{\mathrm{kk}}^{\mathrm{k}}$ initialized by $\mathrm{V}$ and of sequence $\Sigma_{\mathrm{jk}}^{\mathrm{k}}$.

If $\Sigma_{j k}^{k}$ converges to zero when $k$ increases, the computation of estimate $\hat{X}_{j / k+1}$ does not necessitate the knowledge of all measurements and we can use only a moving window for updating the past estimates.

\section{Convergence study of the algorithm}

\subsection{Convergence of sequence $\Sigma_{\mathrm{k} k}^{\mathrm{k}}$}

For sequence $\Sigma_{\mathrm{kk}}^{\mathrm{k}}$ we have sufficient convergence conditions based on the use of a Riccati equation. Also we have necessary and sufficient conditions based on the continued fractions. 
In fact, if $\mathrm{E}$ is a full row rank matrix, by using the inversion lemma, we can write expression (16) as the following Riccati equation

$$
V_{k+1}=D+F V_{k} F^{T}-F V_{k} B^{T}\left(B V_{k} B^{T}+R\right)^{-1} B V_{k} F^{T}
$$

with $\mathrm{F}=\mathrm{VE}^{\mathrm{T}}\left(\mathrm{EVE}^{\mathrm{T}}\right)^{-1} \mathrm{~B}, \mathrm{R}=\mathrm{EVE}^{\mathrm{T}}, \mathrm{D}=\mathrm{V}-\mathrm{VE}^{\mathrm{T}}\left(\mathrm{EVE}^{\mathrm{T}}\right)^{-1} \mathrm{EV}$ and $\mathrm{V}_{\mathrm{k}}=\Sigma_{\mathrm{kk}}^{\mathrm{k}}$ where $\mathrm{R}$ is a positive definite matrix and $\mathrm{D}$ is a semi-positive definite matrix.

Sufficient conditions for the convergence of (35) are given by Caines (1988) in the following theorem.

\section{Theorem 3}

If the pair $(\mathrm{B}, \mathrm{F})$ is detectable and the pair $(\mathrm{F}, \mathrm{S})$ is stabilizable where $\mathrm{S}$ is any square root matrix of $\mathrm{D}$, then given any symmetric positive matrix $\mathrm{V}_{0}$, the sequence of solutions $\left\{\mathrm{V}_{\mathrm{k}}, \mathrm{k}\right.$ is a positive integer $\}$ generated by (35) converges to the unique symmetric positive solution $\mathrm{Y}$ to the algebraic Riccati equation

$$
Y=D+F Y F^{T}-F Y B^{T}\left(B Y B^{T}+R\right)^{-1} B Y F^{T}
$$

Now, we can study the convergence conditions from the matrix continued fractions theory.

From equations (16) and (19), we have

$$
\Gamma_{\mathrm{k}+1}=\mathrm{S}-\mathrm{C} \Gamma_{\mathrm{k}}^{-1} \mathrm{C}^{\mathrm{T}}
$$

where $\Gamma_{\mathrm{k}}=\Omega_{\mathrm{k}}^{-1}, \Gamma_{1}=\mathrm{S}=\mathrm{B} \mathrm{V} \mathrm{B}^{\mathrm{T}}+\mathrm{E} \mathrm{V} \mathrm{E}^{\mathrm{T}}$ and $\mathrm{C}=\mathrm{B} \mathrm{V} \mathrm{E}$.

Relation (37) can be written as a matrix continued fraction

$$
\Gamma_{\mathrm{k}+1}=\mathrm{S}-\mathrm{C}\left(\mathrm{S}-\mathrm{C}\left(\ldots\left(\mathrm{S}-\mathrm{C} \Gamma_{1}^{-1} \mathrm{C}^{\mathrm{T}}\right)^{-1} \ldots\right)^{-1} \mathrm{C}^{\mathrm{T}}\right)^{-1} \mathrm{C}^{\mathrm{T}}
$$

Convergence conditions of this sequence are given from the following theorem (Hallin 1984, 1989).

\section{Theorem 4}

A matrix continued fraction defined by the formal expression $\mathrm{F}$

$$
\mathrm{F}=\mathrm{S}_{0}-\mathrm{C}_{0}\left(\mathrm{~S}_{1}-\mathrm{C}_{1}\left(\mathrm{~S}_{2}-\mathrm{C}_{2}(\ldots)^{-1} \mathrm{C}_{2}^{\mathrm{T}}\right)^{-1} \mathrm{C}_{1}^{\mathrm{T}}\right)^{-1} \mathrm{C}_{0}^{\mathrm{T}}
$$

is positive definite if and only if the associated matrix $R$ 


$$
\mathrm{R}=\left(\begin{array}{ccccc}
\mathrm{S}_{0} & \mathrm{C}_{0} & 0 & 0 & \ldots \\
\mathrm{C}_{0}^{\mathrm{T}} & \mathrm{S}_{1} & \mathrm{C}_{1} & 0 & \ldots \\
0 & \mathrm{C}_{1}^{\mathrm{T}} & \mathrm{S}_{2} & \mathrm{C}_{2} & . \\
. & . & . & . & . \\
. & . & . & . & .
\end{array}\right)
$$

is positive definite. Its approximant $\mathrm{F}^{(\mathrm{n})}$ ( $\mathrm{n}$ is a positive integer) is given by

$$
\mathrm{F}^{(\mathrm{n})}=\mathrm{S}_{0}-\mathrm{C}_{0}\left(\mathrm{~S}_{1}-\mathrm{C}_{1}\left(\ldots \mathrm{C}_{\mathrm{n}-1} \mathrm{~S}_{\mathrm{n}}^{-1} \mathrm{C}_{\mathrm{n}-1}^{\mathrm{T}} \ldots\right)^{-1} \mathrm{C}_{1}^{\mathrm{T}}\right)^{-1} \mathrm{C}_{0}^{\mathrm{T}}
$$

(i) all $\mathrm{F}^{(\mathrm{n})}$ are positive definite,

(ii) $\mathrm{F}^{(\mathrm{n})}-\mathrm{F}^{(\mathrm{n}-1)}$ is positive definite, $\mathrm{n} \in \mathbf{N}$,

(iii) it converges and its value is positive semi-definite matrix $\mathrm{F}$,

(iv) if we consider the positive definite matrix continued fraction

$$
S_{1}-C_{1}\left(\ldots C_{n-1} S_{n}^{-1} C_{n-1}^{T} \ldots\right)^{-1} C_{1}^{T}
$$

it converges to a positive definite value $\mathrm{F}^{(1)}=\mathrm{C}_{0}\left(\mathrm{~S}_{0}-\mathrm{F}\right)^{-1} \mathrm{C}_{0}^{\mathrm{T}}$ and its approximants also satisfy (i) and (ii).

Necessary and sufficient convergence conditions of the sequence $\Gamma_{\mathrm{k}}$ (38) can be given by the following theorem.

\section{Theorem 5}

Sequence $\Gamma_{\mathrm{k}}$ converges to $\Gamma$ if and only if the matrix pencil $(\mathrm{sE}-\mathrm{B})$ is a full row rank matrix.

\section{Proof}

From theorem 1, the pencil matrix $(\mathrm{sE}-\mathrm{B})$ is a full row rank matrix if and only if solution (6) is unique, then the matrix $R=\left(\Phi_{k} \cup \Phi_{k}^{T}\right)$ is non singular. This matrix is positive definite and given by expression (40) with $\mathrm{S}_{0}=\mathrm{S}_{\mathrm{i}}=\mathrm{S}$ and $\mathrm{C}_{0}=\mathrm{C}_{\mathrm{i}}=\mathrm{C}$ for all $\mathrm{i}$. Consequently, from theorem 4 the matrix $\Gamma_{\mathrm{k}}$ given by (38) converges to $\Gamma$.

From this theorem we can deduce that sequence $\Gamma_{\mathrm{k}}$ is a positive definite matrix continued fraction which converges to the positive definite matrix $\Gamma$.

Consequently, sequence $\Omega_{\mathrm{k}}$ converges to $\Omega$ and sequence $\Sigma_{\mathrm{kk}}^{\mathrm{k}}$ converges to $\Sigma_{\mathrm{c}}$

$$
\Sigma_{\mathrm{c}}=\mathrm{V}-\mathrm{VE}^{\mathrm{T}} \Omega \mathrm{EV}=\mathrm{V}-\mathrm{VE}^{\mathrm{T}} \Gamma^{-1} \mathrm{E} \mathrm{V}
$$

\subsection{Convergence of sequence $\Sigma_{\mathbf{j k}}^{\mathrm{k}}(\mathbf{j}<\mathbf{k})$}

From the expression (18) we have the difference matrix equation 


$$
\mathrm{Y}_{\mathrm{k}+1}=\Psi_{\mathrm{k}} \mathrm{Y}_{\mathrm{k}}
$$

with $\mathrm{Y}_{\mathrm{k}}^{\mathrm{T}}=\Sigma_{\mathrm{jk}}^{\mathrm{k}} \mathrm{B}^{\mathrm{T}}$ and $\Psi_{\mathrm{k}}=\mathrm{BVE} \mathrm{E}^{\mathrm{T}} \Omega_{\mathrm{k}}$. We can associate to the relation (44), the following discrete state equation

$$
\mathrm{y}_{\mathrm{k}+1}=\Psi_{\mathrm{k}} \mathrm{y}_{\mathrm{k}}
$$

where $y_{k}$ is a $p$ state vector. The solution of this state equation is

$$
\mathrm{y}_{\mathrm{k}}=\Lambda\left(\mathrm{k}, \mathrm{k}_{0}\right) \mathrm{y}_{\mathrm{k}_{0}}
$$

with

$$
\Lambda\left(\mathrm{k}, \mathrm{k}_{0}\right)=\mathrm{Y}_{\mathrm{k}} \mathrm{Y}_{\mathrm{k}_{0}}^{-1}
$$

The convergence of the sequence $\Sigma_{\mathrm{jk}}^{\mathrm{k}}(\mathrm{j}<\mathrm{k})$ is then reduced to the stability of the null solution of (45). This stability is given by the following theorem (Willems 1970).

\section{Theorem 6}

If the matrix $\Psi_{\mathrm{k}}$ is bounded, then the null solution of (45) is uniformly asymptotically stable if and only if a non-stationary decrescent positive definite Lyapunov function exists whose difference along the solution of (45) is given by decrescent, negative definite, non-stationary quadratic form.

\section{Application to state and input estimation}

Let us consider the linear discrete system described by

$$
\mathrm{x}_{\mathrm{i}+1}=\mathrm{Gx}_{\mathrm{i}}+\mathrm{H} \mathrm{u}_{\mathrm{i}}
$$

where $\mathrm{x}_{\mathrm{i}} \in \mathbf{R}^{\mathrm{n}}, \mathrm{G} \in \mathbf{R}^{\mathrm{n} * \mathrm{n}}, \mathrm{u}_{\mathrm{i}} \in \mathbf{R}^{\mathrm{m}}, \mathrm{H} \in \mathbf{R}^{\mathrm{n} * \mathrm{~m}}$.

The observation equations are

$$
\begin{aligned}
& z_{i}=x_{i}+v_{i} \\
& y_{i}=u_{i}+w_{i}
\end{aligned}
$$

where

$$
\begin{aligned}
& \mathrm{v}_{\mathrm{i}} \sim \mathrm{N}\left(0, \mathrm{~V}_{\mathrm{x}}\right) \\
& \mathrm{w}_{\mathrm{i}} \sim \mathrm{N}\left(0, \mathrm{~V}_{\mathrm{u}}\right)
\end{aligned}
$$

This system can be written as

$$
\mathrm{EX}_{\mathrm{i}+1}=\mathrm{B} \mathrm{X}_{\mathrm{i}}
$$

where $E=(I \mid 0), B=(G \mid H)$ and $X_{i}=\left(\begin{array}{l}x_{i} \\ u_{i}\end{array}\right)$. 
The estimation problem of $\hat{x}_{i}$ and $\hat{u}_{i}$ based on the measurements is reduced to

$$
\begin{array}{ll}
\operatorname{minimize} & \mathrm{J}=\frac{1}{2} \sum_{\mathrm{i}=1}^{\mathrm{k}+1}\left\|\hat{\mathrm{X}}_{\mathrm{i}}-\mathrm{X}_{\mathrm{i}}\right\|_{\mathrm{V}}^{2} \\
\text { under } & \mathrm{E \textrm {X } _ { \mathrm { i } }}-\mathrm{B} \hat{\mathrm{X}}_{\mathrm{i}-1}=0
\end{array}
$$

where

$$
\mathrm{V}=\left(\begin{array}{cc}
\mathrm{V}_{\mathrm{x}} & 0 \\
0 & \mathrm{~V}_{\mathrm{u}}
\end{array}\right)
$$

The recusive solution of this problem is given by expressions (15)-(19). Obviously, since $E=(\mathrm{I} \mid 0)$ the measurement of the variable $u_{k}$ is not corrected in (15) $\left.\hat{(u}_{\mathrm{k}+1 / \mathrm{k}+1}=\mathrm{y}_{\mathrm{k}+1}\right)$, this is not the case for $\hat{u}_{\mathrm{j} / \mathrm{k}+1}(\mathrm{j}<\mathrm{k}+1)$ computed from (17).

The matrix $\mathrm{E}$ is a full row rank matrix. We can give the sufficient convergence condition for sequences $\Sigma_{\mathrm{kk}}^{\mathrm{k}}$ in the following theorem.

\section{Theorem 7}

Sequence $\Sigma_{\mathrm{kk}}^{\mathrm{k}}$ converges if the system described by (48) is asymptotically stable.

\section{Proof}

If the system described by (48) is asymptotically stable, then $\rho(G)<1$. The matrices $\mathrm{F}, \mathrm{R}, \mathrm{D}$ and $\mathrm{S}$ are given by

$$
\mathrm{F}=\left(\begin{array}{cc}
\mathrm{G} & \mathrm{H} \\
0 & 0
\end{array}\right), \mathrm{R}=\mathrm{V}_{\mathrm{x}}, \mathrm{D}=\left(\begin{array}{cc}
0 & 0 \\
0 & \mathrm{~V}_{\mathrm{u}}
\end{array}\right) \text { and } \mathrm{S}=\left(\begin{array}{cc}
0 & 0 \\
0 & \mathrm{~V}_{\mathrm{u}}^{1 / 2}
\end{array}\right)
$$

The pair

$$
(B, F)=\left((G \mid H),\left(\begin{array}{cc}
G & H \\
0 & 0
\end{array}\right)\right)
$$

is detectable if

$$
\left(F^{T}, B^{T}\right)=\left(\left(\begin{array}{ll}
G^{T} & 0 \\
H^{T} & 0
\end{array}\right),\left(\begin{array}{l}
G^{T} \\
H^{T}
\end{array}\right)\right)
$$

is stabilizable. This can be verified for $\mathrm{K}=(\alpha \mathrm{I} \mid 0)$ with $0<\alpha<1$, since the matrix

$$
F^{T}-B^{T} K=\left(\begin{array}{cc}
(1-\alpha) G^{T} & 0 \\
(1-\alpha) H^{T} & 0
\end{array}\right)
$$

has its eigenvalues lieing within the unit circle. Similarly for 


$$
\mathrm{K}=\left(\begin{array}{cc}
\mathrm{K}_{1} & \mathrm{~K}_{2} \\
0 & 0
\end{array}\right)
$$

we have

$$
\mathrm{F}-\mathrm{SK}=\left(\begin{array}{cc}
\mathrm{G} & \mathrm{H} \\
0 & 0
\end{array}\right)
$$

and, since $\rho(G)<1$, we have $\rho(F-S K)<1$.

From theorem 3 , sequence $\Sigma_{\mathrm{kk}}^{\mathrm{k}}$ converges to $\Sigma_{\mathrm{c}}$.

From theorem 5 we have the necessary and sufficient convergence conditions for sequence $\Sigma_{\mathrm{kk}}^{\mathrm{k}}$ given by the matrix pencil $(\mathrm{sE}-\mathrm{B})=((\mathrm{sI}-\mathrm{G}) \mid \mathrm{H})$ must be a full row rank matrix. This condition is verified for all matrix G. Consequently the convergence of sequence $\Sigma_{\mathrm{kk}}^{\mathrm{k}}$ is guaranteed for systems described by (48)$(50)$.

We present the convergence of sequence $\Sigma_{j \mathrm{k}}^{\mathrm{k}}$ in two particular cases. The first corresponds to the inventory system which is described by $\mathrm{G}=\mathrm{I}$ and the second is the case where $\mathrm{G}^{\mathrm{T}} \mathrm{G}<\mathrm{I}$.

\section{Case 1}

Equation (48) becomes

$$
\mathrm{x}_{\mathrm{i}+1}=\mathrm{x}_{\mathrm{i}}+\mathrm{H} \mathrm{u}_{\mathrm{i}}
$$

Expression (44) can be written

$$
\mathrm{Y}_{\mathrm{k}+1}=\Psi_{\mathrm{k}} \mathrm{Y}_{\mathrm{k}}
$$

where

$$
\Psi_{\mathrm{k}}=\mathrm{V}_{\mathrm{x}} \Omega_{\mathrm{k}}
$$

and from (19) we have

$$
\Omega_{\mathrm{k}}^{-1}=\mathrm{V}_{\mathrm{x}}+\mathrm{B} \Sigma_{\mathrm{kk}}^{\mathrm{k}} \mathrm{B}^{\mathrm{T}}>\mathrm{V}_{\mathrm{x}}
$$

which yields

$$
\Psi_{\mathrm{k}}=\mathrm{V}_{\mathrm{x}} \Omega_{\mathrm{k}}<\mathrm{I}
$$

and $\Psi_{\mathrm{k}}$ is bounded.

If we take as Lyapunov function

$$
\mathrm{Q}_{\mathrm{k}}=\mathrm{Y}_{\mathrm{k}}^{\mathrm{T}} \mathrm{Y}_{\mathrm{k}}
$$

we have 


$$
\mathrm{Q}_{\mathrm{k}+1}-\mathrm{Q}_{\mathrm{k}}=\mathrm{Y}_{\mathrm{k}}^{\mathrm{T}}\left(\Psi_{\mathrm{k}}^{\mathrm{T}} \Psi_{\mathrm{k}}-\mathrm{I}\right) \mathrm{Y}_{\mathrm{k}}=\mathrm{Y}_{\mathrm{k}}^{\mathrm{T}}\left(\Omega_{\mathrm{k}} \mathrm{V}_{\mathrm{x}}^{2} \Omega_{\mathrm{k}}-\mathrm{I}\right) \mathrm{Y}_{\mathrm{k}}=\mathrm{Y}_{\mathrm{k}}^{\mathrm{T}} \Omega_{\mathrm{k}}\left(\mathrm{V}_{\mathrm{x}}^{2}-\Omega_{\mathrm{k}}^{-2}\right) \Omega_{\mathrm{k}} \mathrm{Y}_{\mathrm{k}}
$$

negative definite. In fact

$$
\Omega_{\mathrm{k}}^{-1}=\mathrm{V}_{\mathrm{x}}+\mathrm{C}
$$

where

$$
\begin{aligned}
& \mathrm{C}=\mathrm{B} \Sigma_{\mathrm{kk}}^{\mathrm{k}} \mathrm{B}^{\mathrm{T}} \geq 0 \\
& \Omega_{\mathrm{k}}^{-2}=\left(\mathrm{V}_{\mathrm{x}}+\mathrm{C}\right)^{2}=\mathrm{V}_{\mathrm{x}}^{2}+\mathrm{V}_{\mathrm{x}} \mathrm{C}+\mathrm{C} \mathrm{V}_{\mathrm{x}}+\mathrm{C}^{2}
\end{aligned}
$$

which gives $\Omega_{\mathrm{k}}^{-2}-\mathrm{V}_{\mathrm{x}}^{2}>0$ if $\mathrm{C} \mathrm{V}_{\mathrm{x}}$ is positive definite. This, is verified because we have the product of a positive definite matrix and a symmetric matrix $\mathrm{V}_{\mathrm{x}}$ with positive eigenvalues (Horn and Johnson p 465, 1988).

\section{Numerical example}

Consider the system described by

$$
\left(\begin{array}{l}
x_{1 i+1} \\
x_{2 i+1}
\end{array}\right)=\left(\begin{array}{l}
x_{1 i} \\
x_{2 i}
\end{array}\right)+\left(\begin{array}{l}
1 \\
1
\end{array}\right) u_{i}
$$

where

$$
\mathrm{V}_{\mathrm{x}}=\left(\begin{array}{rrr}
3 & 0 & 0 \\
0 & 4 & 0
\end{array}\right) \text { and } \mathrm{V}_{\mathrm{u}}=10
$$

Figures 1 and 2 show the obtained curves of $\hat{x}_{1 j / k}$ and $\hat{u}_{j / k}$ for $j \leq k$ from the above results. Figures 3 and 4 show the evolution of $\left\|\Sigma_{\mathrm{k} k}^{\mathrm{k}}\right\|$ and $\left\|\Sigma_{\mathrm{k}}^{\mathrm{k}}\right\|$ respectively.

\section{Case 2}

The system is described by

$$
\mathrm{x}_{\mathrm{i}+1}=\mathrm{Gx}_{\mathrm{i}}+\mathrm{H} \mathrm{u}_{\mathrm{i}}
$$

where $\mathrm{G}^{\mathrm{T}} \mathrm{G}<\mathrm{I}$.

In this case matrix $\Psi_{\mathrm{k}}$ is given by

$$
\Psi_{\mathrm{k}}=\mathrm{G} \mathrm{V}_{\mathrm{x}} \Omega_{\mathrm{k}}
$$

If we take the same Lyapunov function as the first case we obtain

$$
\mathrm{I}-\Psi_{\mathrm{k}}^{\mathrm{T}} \Psi_{\mathrm{k}}=\Omega_{\mathrm{k}}\left(\Omega_{\mathrm{k}}^{-2}-\mathrm{V}_{\mathrm{x}} \mathrm{G}^{\mathrm{T}} \mathrm{GV}_{\mathrm{x}}\right) \Omega_{\mathrm{k}}
$$

must be positive definite, which is verified since $\Omega_{\mathrm{k}}^{-2}>V_{\mathrm{x}}^{2}$ and $\mathrm{V}_{\mathrm{x}}^{2}>\mathrm{V}_{\mathrm{x}} \mathrm{G}^{\mathrm{T}} \mathrm{GV}_{\mathrm{x}}$. 


\section{Numerical example}

Consider the system described by

$$
\left(\begin{array}{l}
x_{1 i+1} \\
x_{2 i+1}
\end{array}\right)=\left(\begin{array}{ll}
0 & 0.3 \\
0.5 & 0.7
\end{array}\right)\left(\begin{array}{l}
x_{1 i} \\
x_{2 i}
\end{array}\right)+\left(\begin{array}{l}
1 \\
1
\end{array}\right) u_{i}
$$

where

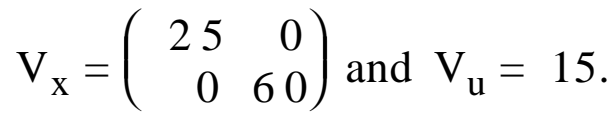

This system is stable and the inequality $G^{T} G<I$ is verified. As in the precedent example, figures 5 and 6 show the curves of $\hat{x}_{1 j / k}$ and $\hat{x}_{2 j / k}$ for $j \leq k$ and figures 7 and 8 those of $\left\|\Sigma_{\mathrm{kk}}^{\mathrm{k}}\right\|$ and $\left\|\Sigma_{\mathrm{jk}}^{\mathrm{k}}\right\|$.

\section{Conclusion}

We have presented a new state estimation algorithm for a class of singular systems. Its convergence conditions are given. Only determinist models were considered, which are generally used in chemical engineering field. In a future publication we shall present a stochastic version of this algorithm.

\section{REFERENCES}

CAINES, P.E., Linear stochastic systems, J. Wiley (1988).

CROWE, C.M., GARCIA COMPOS, Y.A., and HRYMAK, A., "Reconciliation of process flow rates by matrix projection - Part 1 : Linear case", AIChE J, Vol 29, $\mathrm{N}^{\circ} 6$, 881 (1983).

DAI, L., 1989, Filtering and LQG problems for discrete time stochastic singular systems, IEEE Transactions on Automatic Control, Vol AC-34, $\mathrm{N}^{\circ} 10$, pp 11051108 .

DAROUACH, M.,1986, , Observabilité et validation des données de systèmes de très grande dimension. Application à l'équilibrage de bilans de mesures, Thèse de Doctorat es Sciences, Université de Nancy I, France.

DAROUACH, M., J. RAGOT, J., FAYOLLE, J., and MAQUIN, D.,1989, Data validation in large scale steady state linear systems, Computing and Computers for Control Systems, IMACS, pp 351-355.

GANTMACHER, F.R., 1959, The theory of matrices, Chelsea, New-York.

HALLIN, M., 1984, Spectral factorization of nonstationary moving average processes, The Annals of Statistics, Vol 12, $\mathrm{N}^{\circ}$ 1, pp 172-192.

HALLIN, M., 1989, Modèles non stationnaires, séries univariées et multivariées, Séries chronologiques, théorie et pratique des modèles ARIMA, Edité par J.J. Droesbeke, B. Fichet et P. Tassi, Economica, Paris.

HORN, R.A., and JOHNSON, C.R., 1988, Matrix analysis, Cambridge University Press. 
LUENBERGER, D.G., 1977, Dynamic equations in descriptor form, IEEE Transactions on Automatic Control, Vol AC-22, $\mathrm{N}^{\circ} 3$, pp 312-321.

LUENBERGER, D.G., 1978, Time-invariant descriptor systems, Automatica, Vol 14, $\mathrm{N}^{\circ}$ 3, pp 473-480.

VERGHESE, G.C., LEVY, B.C., and KAILATH, T., 1981, A singular state-space for singular systems, IEEE Transactions on Automatic Control, Vol AC-26, $\mathrm{N}^{\circ} 4$, pp 811-831.

WILLEMS, J.C., 1970, Stability theory of dynamical systems, Nelson.

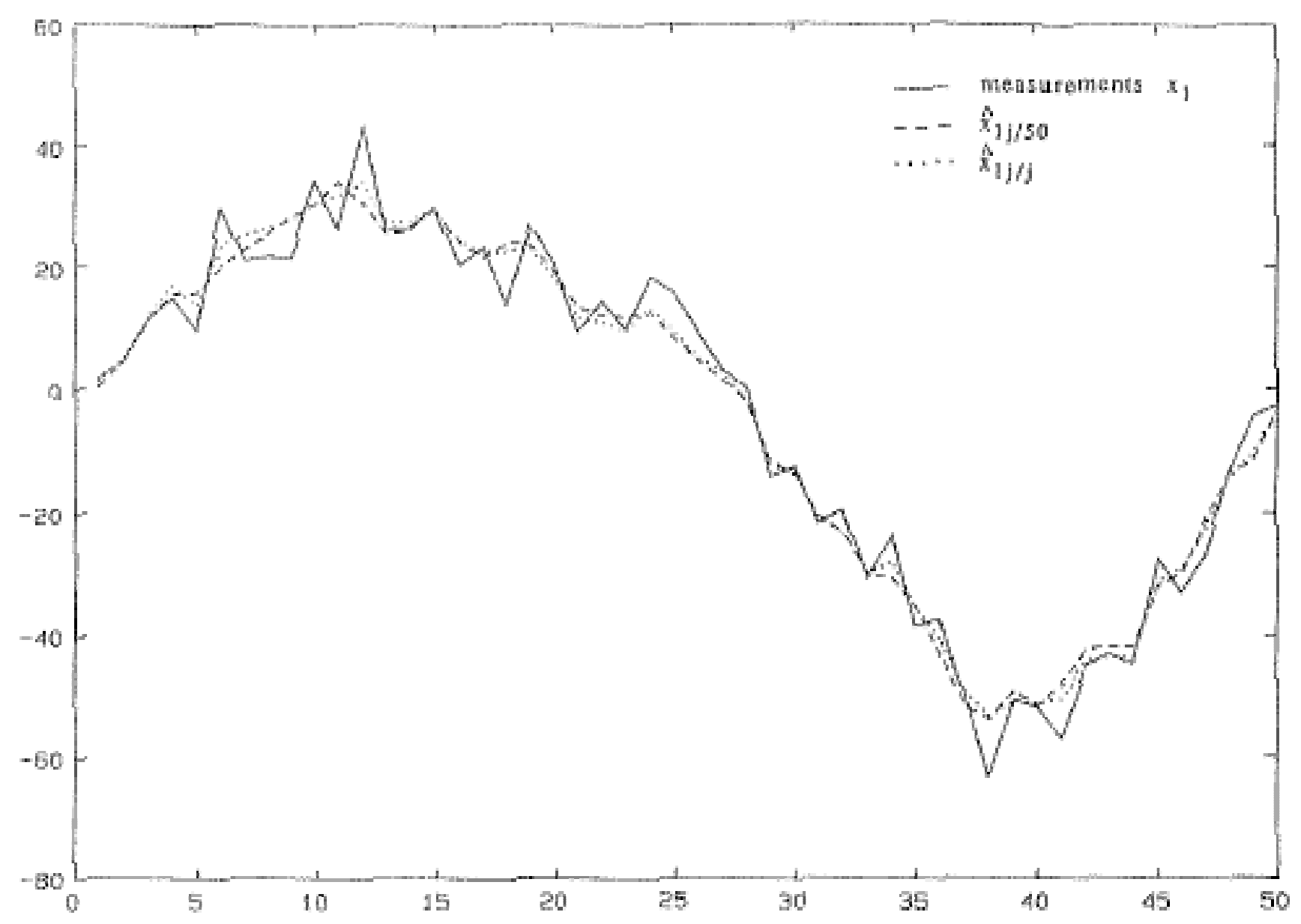

figure 1: measured and estimated values of state variable $\mathrm{x}_{1}$ in case 1 


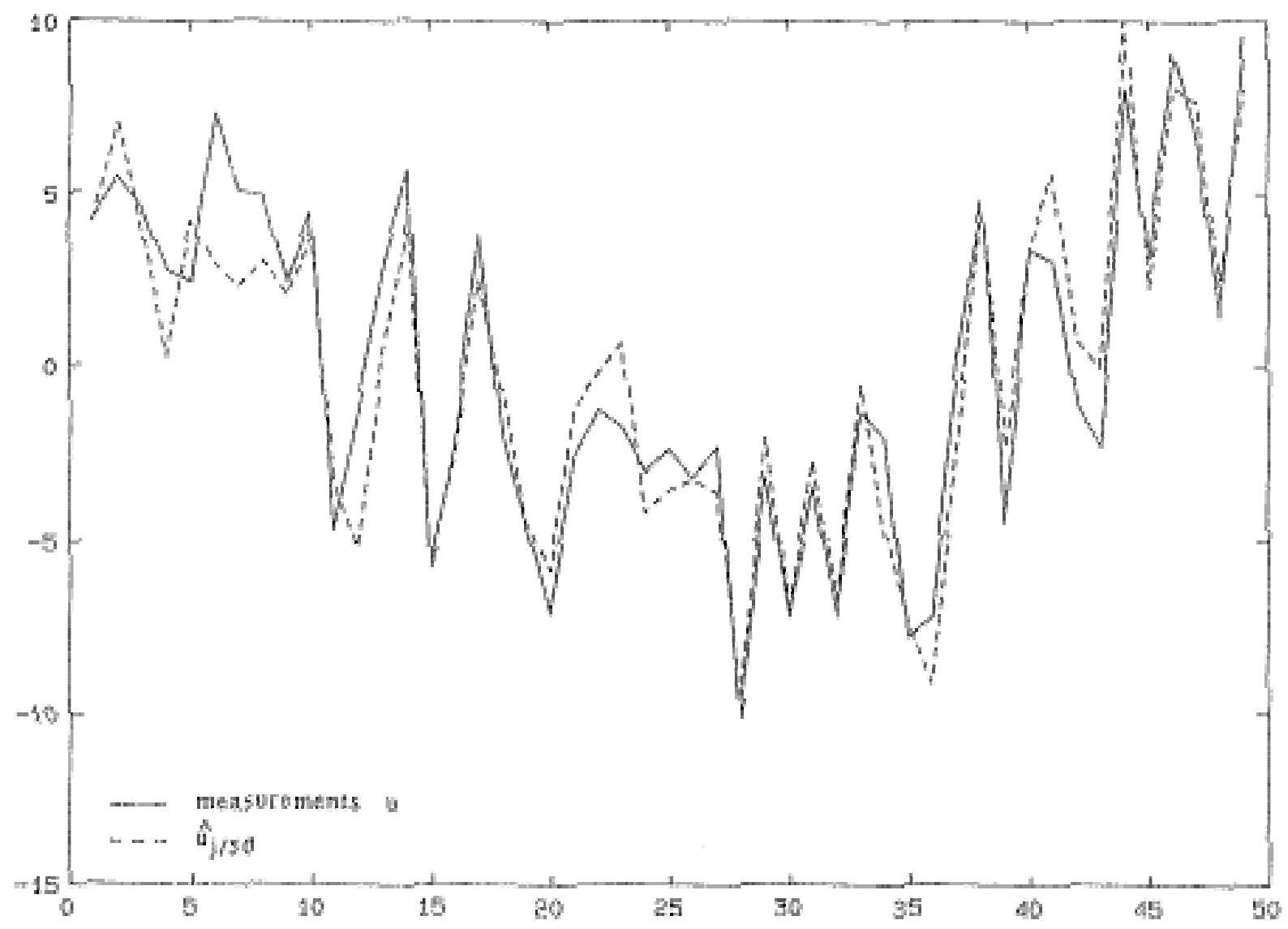

figure 2 : measured and estimated values of input in case 1

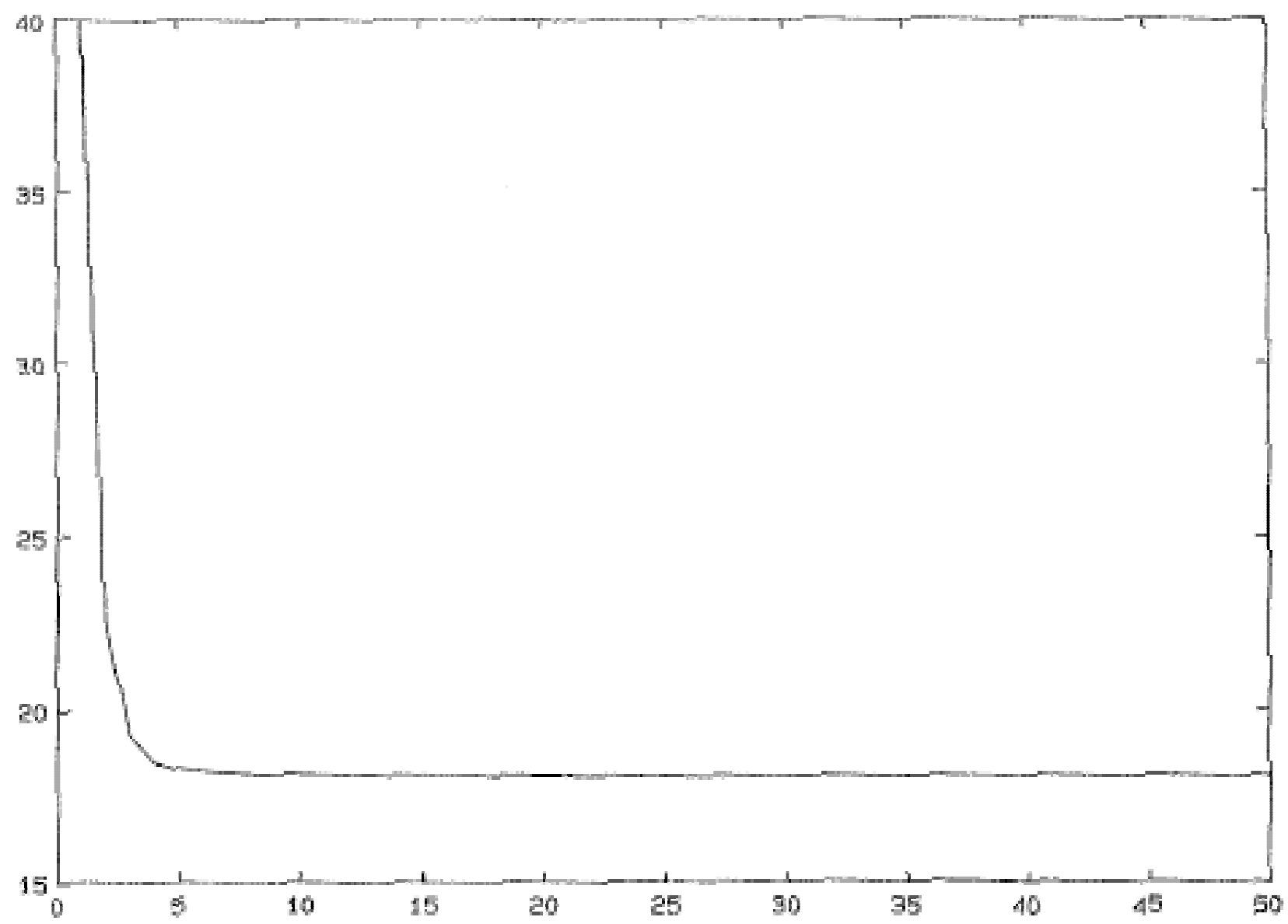

figure 3 : evolution of the norm $\left\|\Sigma_{\mathrm{kk}}^{\mathrm{k}}\right\|$ in case 1 


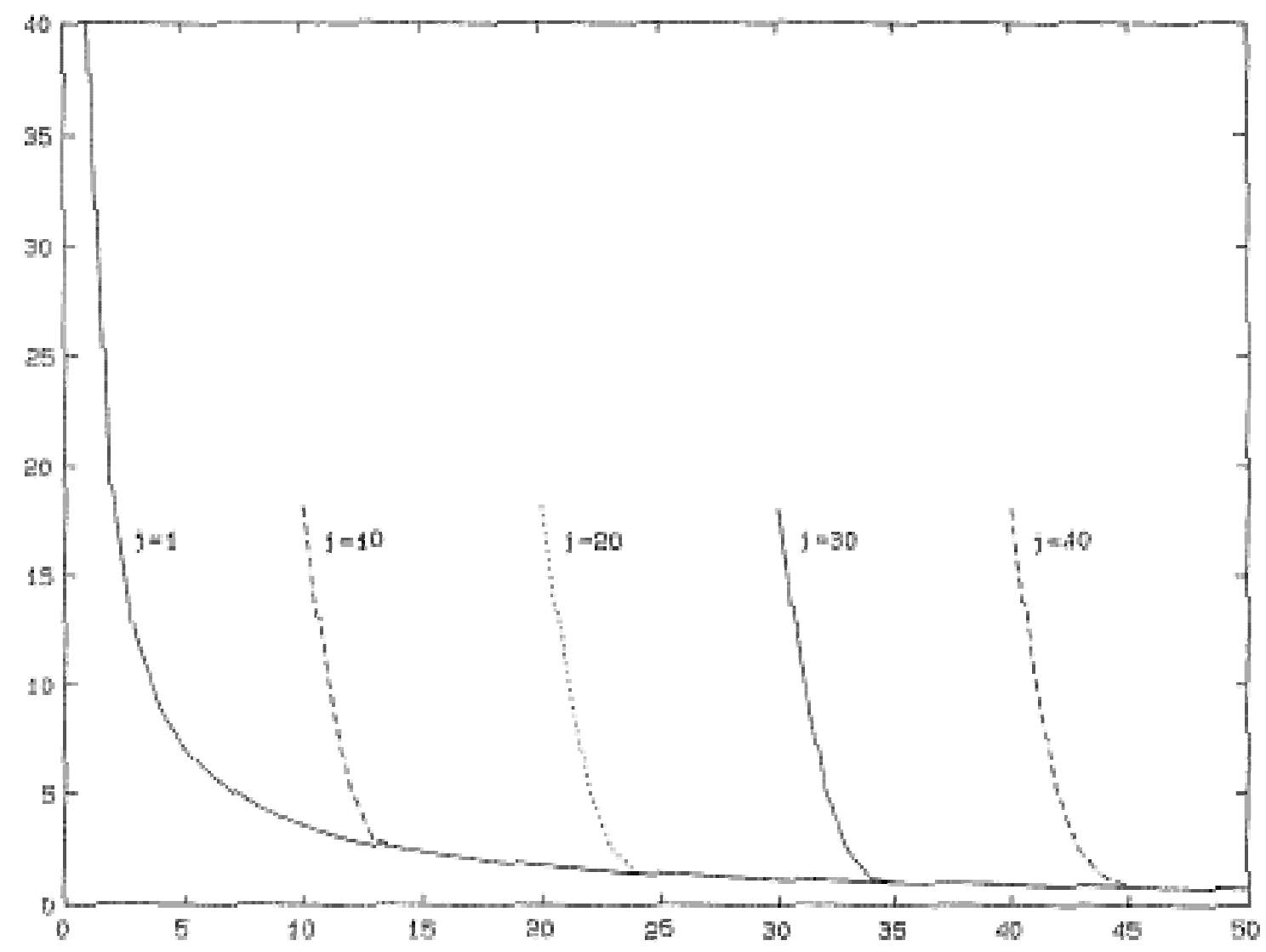

figure 4 : evolution of the norm $\left\|\Sigma_{\mathrm{jk}}^{\mathrm{k}}\right\|$ for $\mathrm{j}=1,10,20,30$ and 40 in case 1

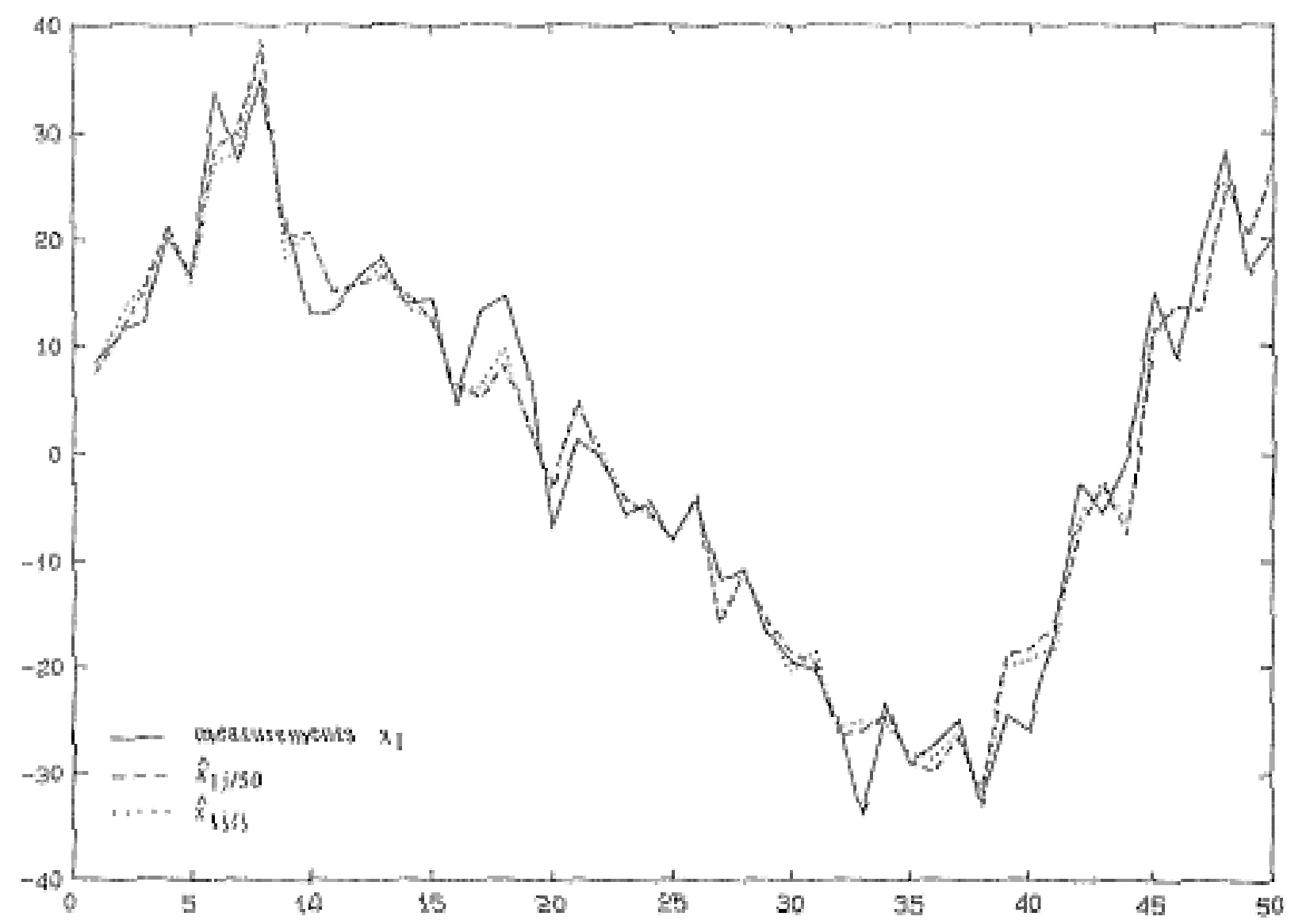

figure 5 : measured and estimated values of state variable $x_{1}$ in case 2 


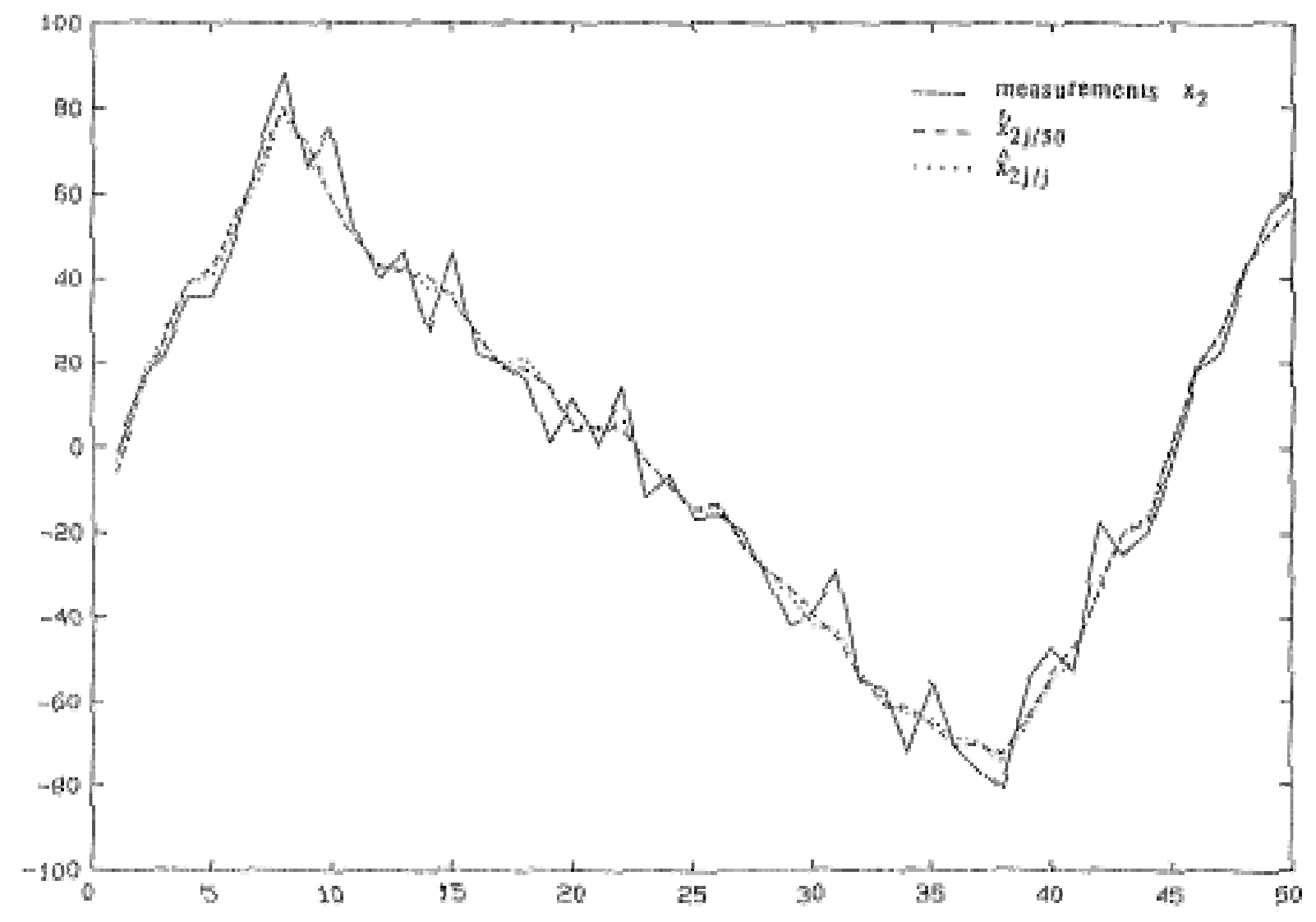

figure 6 : measured and estimated values of state variable $x_{2}$ in case 2

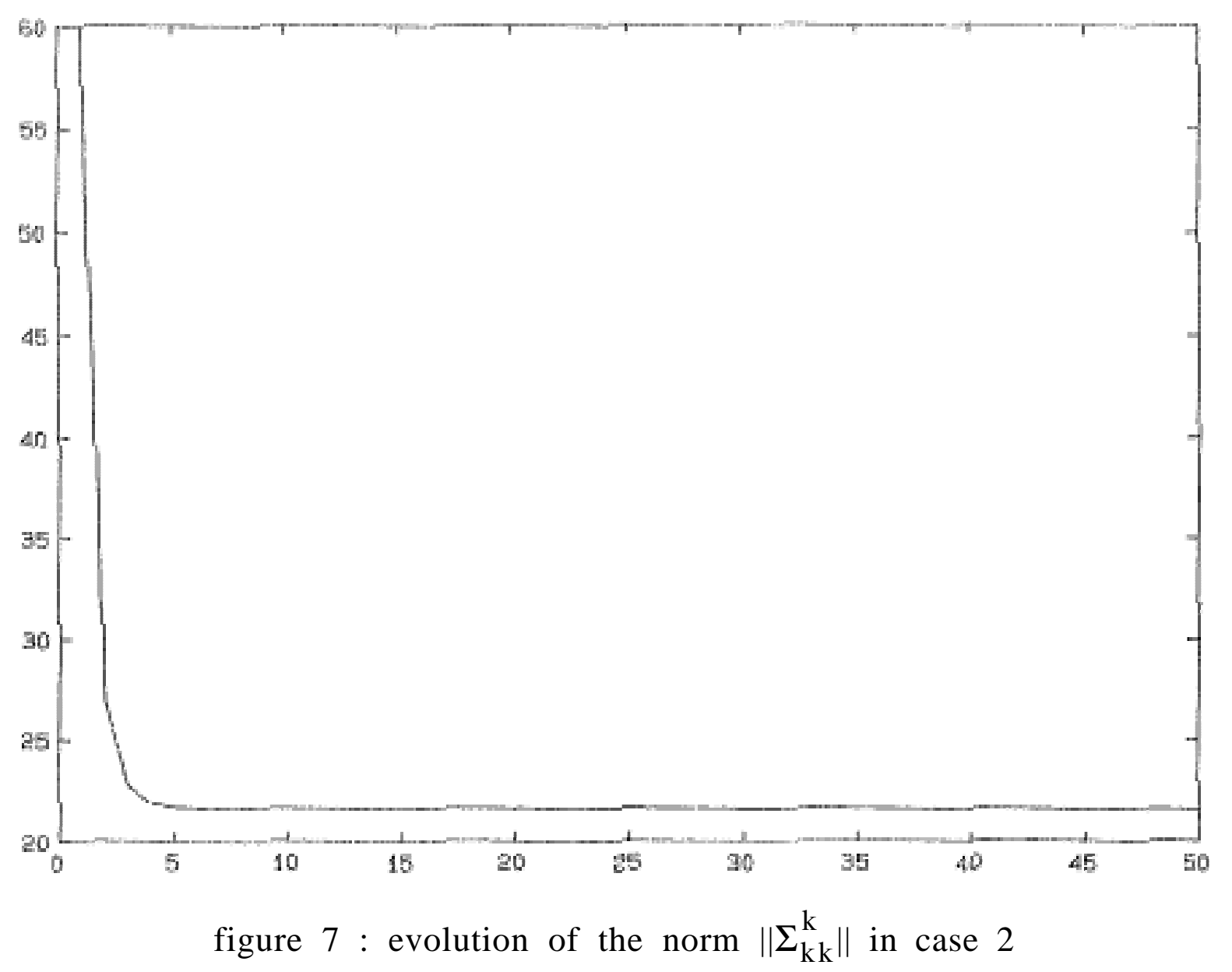

